\title{
Nine months postpartum weight retention predictors for Brazilian
} women

\author{
Gilberto Kac ${ }^{1, *}$, Maria HDA Benicio ${ }^{2}$, Gustavo Velásquez-Meléndez ${ }^{3}$ \\ and Joaquim $G$ Valente ${ }^{4,5}$ \\ 'Department of Social and Applied Nutrition, Institute of Nutrition, Federal University of Rio de Janeiro,
} Av. Brigadeiro Trompowsky s/n ${ }^{\circ}$ - Bloco J - $2^{\circ}$ andar, Rio de Janeiro, RJ 21941-590, Brazil: ${ }^{2}$ Department of Nutrition, School of Public Health, University of São Paulo, São Paulo, SP, Brazil: ${ }^{3}$ Department of Maternal and Pediatric Nursing and Public Health, School of Nursing, Federal University de Minas Gerais, Belo Horizonte, MG, Brazil: ${ }^{4}$ Department of Epidemiology and Quantitative Methods in Health, National School of Public Health, Fundação Oswaldo Cruz, Rio de Janeiro, RJ, Brazil: ${ }^{5}$ Institute of Social Medicine, State University of Rio de Janeiro, Rio de Janeiro, RJ, Brazil

Submitted 3 July 2003: Accepted 25 November 2003

\begin{abstract}
Objective: To identify factors potentially associated with weight retention measured 9 months after childbirth.

Design: Prospective study with four follow-up waves in time (0.5, 2, 6 and 9 months postpartum).

Setting: Rio de Janeiro, Brazil.

Subjects and methods: Two hundred and sixty-six Brazilian women of childbearing age. Analysis was based on hierarchical logistic regression. The dependent variable was weight retention and was defined as the difference between weight at 9 months postpartum and pre-pregnancy weight, with a dichotomised cut-off at $7.5 \mathrm{~kg}$. Covariates included demographic and socio-economic data, obstetric history, anthropometric data, and data on the infant. These data were grouped in blocks and ordered according to their influence on the dependent variable.

Results: Of the women studied, $19.2 \%$ presented weight retention values $\geq 7.5 \mathrm{~kg}$. According to the logistic regression analysis, the following variables remained associated with weight retention $\geq 7.5 \mathrm{~kg}$ : total family income, difficulty or inability to read a letter, age category $\geq 30$ years, age at first childbirth $<23$ years, gestational weight gain $\geq 12 \mathrm{~kg}$, body fat at baseline $\geq 30 \%$ and infant birth weight $<3500 \mathrm{~g}$. Infant hospitalisation was only marginally significant.

Conclusions: Determinant factors identified by the analysis highlight the need for nutritional intervention policies during pregnancy and in the first months postpartum as a way of minimising obesity and the diseases resulting from it.
\end{abstract}

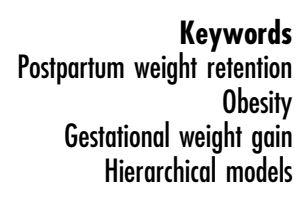

Obesity has been described in recent years as an important public health problem in several European countries ${ }^{1}$, the $\mathrm{USA}^{2}$ and also Brazil ${ }^{3,4}$, due in particular to its important determinant role in the occurrence of cardiovascular diseases, hypertension and diabetes ${ }^{5,6}$.

In Brazil, the few population-based studies on obesity prevalence and trends in women of childbearing age showed an increase of $0.37 \%$ per year from 1989 to $1996^{3}$. This rate was almost twice that observed between 1975 and $1989(0.20 \%)$. This trend served to launch the problem of obesity into the public health agenda of Brazil.

The reproductive cycle as a whole, and especially pregnancy and the subsequent postpartum months, is recognised as a risk period for the development of obesity, manifested principally as postpartum weight retention.
According to recent literature reviews ${ }^{7-9}$, the principal determinants of postpartum weight retention are elevated gestational weight gain $^{10-13}$, high parity ${ }^{14}$ and the intensity and/or duration of lactation ${ }^{15-17}$, although the latter effect is still controversial. The effect of some other factors has been described, including physical exercise ${ }^{18}$ and dietary intake.

It is important to highlight that, among the studies on postpartum weight retention reviewed in the literature, there are few epidemiological studies that control potential confounding factors and with the methodological rigor to investigate sociodemographic determinants and lifestyle effects. From this perspective, the current study presents data on weight retention based on a follow-up study of Brazilian women during the first nine months postpartum. 
From a public health perspective, the objective of the investigation is to answer the following question: What are the most important determinants of weight retention? The results are then used to consider which strategies can be implemented to prevent this outcome.

\section{Methods}

The data presented here were obtained from a cohort study, with 9 months' follow-up, on weight retention, body composition and obesity. The study was conducted on Brazilian women, aged 15 to 45 years, residing in the city of Rio de Janeiro, Brazil. The data collection process lasted 24 months (15 months of recruitment and 9 months of follow-up), from May 1999 to April 2001.

\section{Recruitment and selection of participants}

The participants were women of childbearing age who consented to enter the study. Women were recruited at three different times at different sites: (1) at the central maternity hospital in the study area, in the immediate postpartum period ( $n=229,32.3 \%)$; (2) during thirdtrimester prenatal consultations ( $n=268,37.8 \%)$; and (3) during routine (BCG) immunisation against tuberculosis $(n=212,29.9 \%)$. We searched the central maternity hospital for women meeting the eligibility criteria (see below) three times a week for 15 months, alternating the week days every other week, including Saturdays and Sundays. All prenatal consultations were monitored during the 15-month recruitment period. Pregnant women over 28 weeks of gestation were invited to enter the study after childbirth. Finally, women were also recruited during BCG immunisation, which routinely took place three days a week. These women were usually invited to enter the study the same day. Recruitment during prenatal care and routine BCG immunisation was conducted by the principal researcher (G.K.); in the maternity hospital, recruitment was done by three medical interns who had been trained according to a standardised protocol.

A total of 709 women were recruited and 479 entered the cohort. Women recruited at the three different sites presented similar profiles in terms of age, pre-pregnancy weight, schooling and parity, and also similar patterns of loss to follow-up.

\section{Eligibility criteria}

Eligibility criteria for entering the cohort were: age from 15 to 45 years, less than 30 days elapsed postpartum on the date of the first interview, absence of chronic diseases, gestational age at delivery $\geq 37$ weeks, no history of multiple gestation, and residence in the study area.

For the purposes of this analysis, the only other eligibility criterion implemented was having age $\geq 18$ years $(n=47)$. The following exclusion criteria were also implemented: no information on pre-pregnancy weight $(n=13)$, having postpartum weight retention outside the range -10.0 to $+16.0 \mathrm{~kg}(Z$-score $<-3$ and $>3, n=14)$ and not having participated in all four follow-up interviews $(n=134)$. Additionally, five women were excluded because of lack of anthropometric data for the third follow-up appointment, producing a final sample of 266 women.

\section{Etbical aspects}

The study was approved by the research ethics committee at the Centre for Collective Heath Studies of the Federal University of Rio de Janeiro (NESC/UFRJ), and by the research ethics committee at the School of Public Health of São Paulo University. All participants signed a written term of consent.

\section{Characteristics of the follow-up study}

All study participants were interviewed in the Marcolino Candau Municipal Health Centre according to a longitudinal design that included four follow-up waves, at 0.5, 2, 6 and 9 months postpartum, approximately. The appointments were planned to coincide with the basic infant immunisation scheme. Mothers were queried on various demographic, socio-economic and reproductive issues, and history of diseases. The women were also weighed on a digital electronic scale (Filizolla PL 150; Filizolla Ltda., Brazil), measured on a Holtain-Harpenden anthropometer (Holtain-Harpenden, UK) and evaluated for body composition at all four follow-up visits using the electrical impedance technique (BIA 101Q; RJL Inc., USA), according to standardised conditions of hydration and physical activity. Percentage body fat was estimated through the equations provided by RJL, and only percentage body fat at baseline was used as a predictor in the present study. All procedures were performed by the principal investigator (G.K.), using standardised techniques ${ }^{19}$.

\section{Study of losses to follow-up}

The pattern of loss to follow-up was evaluated after implementation of the criteria described above, based on the comparison of selected characteristics among the following subgroups: women who completed follow-up $(n=271)$ and women lost to follow-up, regardless of when the losses occurred $(n=134)$. The women were compared using the final follow-up rate on selected variables from the questionnaire applied during the first interview. These included demographic variables such as age category (18-19, 20-24, 25-29 and 30-45 years) and marital status (single, living with a partner, married); socioeconomic variables such as employment status in the previous 12 months (yes, no, never worked) and total family income, expressed in quartiles (Q1, Q2, Q3, Q4); lifestyle variables like smoking (current smoker, former smoker, never smoked); and nutritional status variables including dichotomised pre-pregnancy weight $(<56 \mathrm{~kg}$, $\geq 56 \mathrm{~kg})$, stature $(<159 \mathrm{~cm}, \geq 159 \mathrm{~cm})$, body fat measured by impedance $(<30 \%, \geq 30 \%)$ and weight retention at first 
interview $\geq 7.5 \mathrm{~kg}(<7.5 \mathrm{~kg}, \geq 7.5 \mathrm{~kg})$. The chi-square test for proportions was used and only some of these variables are presented in Table 1.

\section{Dependent variable and covariates}

The dependent variable used for analyses in the current study was 9 months postpartum weight retention. To construct this variable, the variable absolute weight retention at 9 months postpartum was initially created, calculated by subtracting the mother's pre-pregnancy weight, as reported by the mother herself, from her weight at 9 months postpartum. Absolute weight retention was then dichotomised. Thus, weight retention $\geq 7.5 \mathrm{~kg}$ at 9 months postpartum was the dependent variable. This cut-off was adopted since it corresponded to 2.4 times the mean weight retention value at 9 months for this sample, thus representing a substantial amount of weight retention. Another reason for using this cut-off was the fact that it represented approximately $20 \%$ of the study population, which could be considered a public health problem.

Several covariates were included in the analysis. These variables were selected from a database with information gathered in the first interview. These data were obtained through a direct interview with the mother, using a structured questionnaire with pre-coded questions. Covariate categories were defined according to consolidated cut-off points or according to median values for dichotomised variables. The following covariates were included in the analysis according to hierarchical blocks:
1. Block of socio-economic and demographic variables total family income during the study period in quartiles $(0-279,280-499,500-869,870-5500$ reais), difficulty in reading a letter (no, yes), years of schooling $(\leq 4, \geq 5)$, skin colour (black, brown, white), marital status (married, living with partner, single), place of birth (born in the State of Rio de Janeiro, born in another State of Brazil), age category (18-19, 20-29, 30-45 years) and gender of head of family (male, female).

2. Block of reproductive variables - age at menarche $(<12, \geq 12$ years), parity $(1,2,3, \geq 4)$ and mother's age at first childbirth $(<23, \geq 23$ years $)$.

3. Block related to mother's nutritional status and smoking habits - stature $(<159, \geq 159 \mathrm{~cm})$, presence of obesity (total body fat $\geq 30 \%$ ) according to impedance $(<30$, $\geq 30 \%)$, pre-pregnancy body mass index $(<25$, $\geq 25 \mathrm{~kg} \mathrm{~m}^{-2}$ ), gestational weight gain $(<9.0,9.0-11.9$, $12.0-15.9, \geq 16.0 \mathrm{~kg}$ ) and smoking status (smoker or former smoker, never smoked). (Gestational weight gain was reported as the mother's answer the following question: How much weight did you gain in your last pregnancy? Fifty-eight women could not answer this question. As the odds ratio (OR) for these women was 4.3 , and the OR for the risk group was 4.1, they were included in the risk category at the final model.)

4. Block related to the infant - hospitalisation of the infant during the 9 months of follow-up (yes, no) and infant's birth weight $(<3500, \geq 3500 \mathrm{~g})$.

Table 1 Frequency distribution of selected variables between loss and complete follow-up and final follow-up rate for Brazilian women aged 18-45 years (Rio de Janeiro, 1999-2001)

\begin{tabular}{|c|c|c|c|c|c|}
\hline Variable & Initial number of observations & Losses to follow-up $(n)$ & Complete follow-up $(n)$ & Final follow-up rate (\%) & $P$-value* \\
\hline \multicolumn{6}{|c|}{ Age category (years) } \\
\hline $18-19$ & 60 & 36 & 24 & 40.0 & \\
\hline $20-24$ & 136 & 42 & 94 & 69.1 & \\
\hline $25-29$ & 114 & 38 & 76 & 66.7 & \\
\hline $30-45$ & 95 & 18 & 77 & 81.0 & 0.0039 \\
\hline \multicolumn{6}{|l|}{ Marital status } \\
\hline Single & 74 & 18 & 56 & 75.7 & \\
\hline With partner & 230 & 76 & 154 & 66.9 & \\
\hline Married & 101 & 40 & 61 & 60.4 & 0.1172 \\
\hline \multicolumn{6}{|c|}{ Work in the last 12 months } \\
\hline Yes & 251 & 79 & 172 & 68.5 & \\
\hline No & 120 & 42 & 78 & 65.0 & \\
\hline Never worked & 34 & 13 & 21 & 61.8 & 0.7644 \\
\hline \multicolumn{6}{|c|}{ Total family income (reais) } \\
\hline Q1 (0-279) & 86 & 34 & 52 & 60.5 & \\
\hline Q2 (280-499) & 109 & 36 & 73 & 67.0 & \\
\hline Q3 (500-869) & 96 & 25 & 71 & 73.9 & \\
\hline Q4 (870-5500) & 114 & 39 & 75 & 65.8 & 0.4551 \\
\hline \multicolumn{6}{|c|}{ Pre-pregnancy weight (kg) } \\
\hline$<56$ & 194 & 63 & 131 & 67.5 & \\
\hline$\geq 56$ & 211 & 71 & 140 & 66.3 & 0.8961 \\
\hline \multicolumn{6}{|l|}{ Body fat (\%) } \\
\hline$<30$ & 195 & 59 & 136 & 69.7 & \\
\hline$\geq 30$ & 210 & 75 & 135 & 64.3 & 0.3431 \\
\hline \multicolumn{6}{|c|}{ Weight retention (kg) } \\
\hline$<7.5$ & 295 & 96 & 199 & 67.4 & \\
\hline$\geq 7.5$ & 110 & 38 & 72 & 65.4 & 0.7505 \\
\hline
\end{tabular}

${ }^{*} P$-value from chi-square test for proportions. 
Some variables were categorised again for the multivariate analysis.

\section{Data analysis}

Data analysis was performed in three stages. Bivariate analyses were run initially, comparing the prevalence of weight retention $\geq 7.5 \mathrm{~kg}$ at 9 months and various covariables. The existence of differences was evaluated by the chi-square test. The second stage involved calculating unadjusted ORs and the respective 95\% confidence intervals (CIs). The third and final stage was nonconditional, hierarchical multivariate logistic regression analysis, using the procedures indicated by Hosmer and Lemeshow $^{20}$ and Victora et al. $^{21}$, estimating the ORs and 95\% CIs. Variables displaying an association $(P<0.20)$ with the dependent variable were included in the subsequent multivariate analyses. The theoretical model for weight retention determinants oriented the structuring of blocks and sub-blocks of variables and thus the order in which they entered the model. The more distal factors in the block (socio-economic and demographic factors) were the first to be included in the model, and those displaying an association $(P<0.20)$ with weight retention remained as adjustment factors for the hierarchically inferior variables. All procedures were performed with SPSS for Windows, version 10.07 (SPSS Inc., Chicago, IL, USA).

\section{Results}

No differences were observed in the four key variables (age, pre-pregnancy weight, parity and schooling) used to evaluate the presence of selection bias between the women recruited and those finally included in the study (results not shown). Table 1 presents data on the pattern of losses among women with complete follow-up and those who were lost to follow-up. No differences were observed in the final follow-up rate for any of the study variables, except for age category.

Tables 2 and 3 present prevalence data, unadjusted ORs and 95\% CIs for demographic, socio-economic, reproductive, anthropometric and infant-related variables for women with weight retention $\geq 7.5 \mathrm{~kg}$. As shown in Table 2, weight retention was associated in the bivariate analysis with black skin colour, difficulty in reading a letter and total family income during the study period.

Table 2 Prevalence, odds ratio (OR) and 95\% confidence interval $(\mathrm{Cl})$ for 9 months postpartum weight retention $\geq 7.5 \mathrm{~kg}$, by demographic and socio-economic factors, among Brazilian women aged 18-45 years (Rio de Janeiro, 1999-2001)

\begin{tabular}{|c|c|c|c|c|}
\hline Variable & \multicolumn{4}{|c|}{ Nine months postpartum weight retention $\geq 7.5 \mathrm{~kg}$} \\
\hline Married & 55 & 21.8 & $1.58(0.60-4.10)$ & 0.3472 \\
\hline With partner & 151 & 19.9 & $1.40(0.62-3.17)$ & 0.4132 \\
\hline Single & 60 & 15.0 & 1.00 & \\
\hline Outside Rio de Janeiro & 94 & 13.8 & 1.00 & \\
\hline \multicolumn{5}{|l|}{ Age category (years) } \\
\hline $18-19$ & 32 & 12.5 & 1.00 & \\
\hline $20-29$ & 165 & 17.6 & $1.49(0.49-4.57)$ & \\
\hline $30-45$ & 69 & 26.1 & $2.46(0.76-8.00)$ & $0.1957 \dagger$ \\
\hline \multicolumn{5}{|l|}{ Skin colour } \\
\hline Male & 201 & 20.9 & $1.64(0.75-3.58)$ & 0.2133 \\
\hline Female & 65 & 13.8 & 1.00 & \\
\hline \multicolumn{5}{|l|}{ Can read a letter } \\
\hline No & 40 & 32.5 & $2.38(1.12-5.03)$ & 0.0229 \\
\hline Yes & 226 & 16.8 & 1.00 & \\
\hline \multicolumn{5}{|l|}{ Smoking status } \\
\hline Smoker or former smoker & 80 & 23.8 & $1.50(0.79-2.84)$ & 0.2155 \\
\hline Never smoked & 186 & 17.2 & 1.00 & \\
\hline \multicolumn{5}{|l|}{ Total family income (reais) } \\
\hline Q1 (0-279) & 51 & 23.5 & $3.38(1.17-9.73)$ & \\
\hline Q2 (280-499) & 72 & 20.8 & $2.89(1.05-7.95)$ & \\
\hline Q3 (500-869) & 71 & 25.4 & $3.73(1.38-10.07)$ & \\
\hline
\end{tabular}

* $P$-value for OR.

$\dagger P$-value for linear trend. 
In the set of obstetric variables, mother's age at first childbirth $<23$ years and parity were associated with weight retention $\geq 7.5 \mathrm{~kg}$ at 9 months postpartum (Table 3 ). Other associated variables were gestational weight gain, obesity (body fat $\geq 30 \%$ ), infant's hospitalisation during the 9 months of follow-up, and infant's birth weight $<3500 \mathrm{~g}$.

In the final model, the following variables remained associated with weight retention $\geq 7.5 \mathrm{~kg}$ at 9 months postpartum: total family income, age category $\geq 30$ years, age at first delivery $<23$ years, gestational weight gain $\geq 12 \mathrm{~kg}$ and body fat $\geq 30 \%$. Difficulty or inability to read a letter, infant's hospitalisation and infant's birth weight $<3500$ g presented a strong tendency towards significance and were kept at the final model (Table 4).

\section{Discussion}

The objective of this study was to identify factors associated with postpartum weight retention $\geq 7.5 \mathrm{~kg}$ among a group of Brazilian women. The results of the final

Table 3 Prevalence, odds ratio (OR) and 95\% confidence interval (Cl) for 9 months postpartum weight retention $\geq 7.5 \mathrm{~kg}$, by reproductive factors and nutritional status, among Brazilian women aged 18-45 years (Rio de Janeiro, 1999-2001)

\begin{tabular}{|c|c|c|c|c|}
\hline \multirow[b]{2}{*}{ Variable } & \multicolumn{4}{|c|}{$\begin{array}{l}\text { Nine months postpartum weight retention } \\
\qquad \geq 7.5 \mathrm{~kg}\end{array}$} \\
\hline & $n$ & $\begin{array}{l}\text { evalence } \\
(\%)\end{array}$ & OR $(95 \% \mathrm{Cl})$ & $P$-value* \\
\hline \multicolumn{5}{|c|}{ Age at menarche (years) $\dagger$} \\
\hline$<12$ & 53 & 22.2 & $1.32(0.63-2.75)$ & 0.4521 \\
\hline$\geq 12$ & 210 & 18.4 & 1.00 & \\
\hline \multicolumn{5}{|c|}{ Mother's age at first childbirth (years) $\dagger$} \\
\hline$<23$ & 183 & 23.5 & $2.84(1.27-6.35)$ & 0.0111 \\
\hline$\geq 23$ & 82 & 9.8 & 1.00 & \\
\hline \multicolumn{5}{|c|}{ Parity (number of children) $\dagger$} \\
\hline 1 & 108 & 12.0 & 1.00 & \\
\hline 2 & 82 & 18.3 & $1.63(0.73-3.66)$ & \\
\hline 3 & 46 & 28.3 & $2.87(1.21-6.83)$ & \\
\hline$\geq 4$ & 29 & 34.5 & $3.84(1.47-10.05)$ & $0.0200 \ddagger$ \\
\hline \multicolumn{5}{|c|}{ Infant hospitalisation } \\
\hline Yes & 40 & 37.5 & $3.16(1.52-6.58)$ & 0.0020 \\
\hline No & 226 & 15.9 & 1.00 & \\
\hline \multicolumn{5}{|c|}{ Infant's birth weight (g) } \\
\hline$<3500$ & 203 & 21.7 & $2.17(0.92-5.10)$ & \\
\hline$\geq 3500$ & 63 & 11.1 & 1.00 & 0.0748 \\
\hline \multicolumn{5}{|c|}{ Gestational weight gain $(\mathrm{kg}) \dagger$} \\
\hline$\geq 16.0$ & 56 & 33.9 & $7.35(2.01-26.84)$ & \\
\hline $12.0-15.9$ & 57 & 17.5 & $3.04(0.78-11.81)$ & \\
\hline $9.0-11.9$ & 49 & 8.2 & $1.27(0.27-6.02)$ & \\
\hline$<9.0$ & 46 & 6.5 & 1.00 & $0.0016 \ddagger$ \\
\hline \multicolumn{5}{|c|}{ Pre-pregnancy body mass index $\left(\mathrm{kg} \mathrm{m}^{-2}\right)$} \\
\hline$<25$ & 197 & 25.7 & $1.75(0.91-3.37)$ & 0.0926 \\
\hline$\geq 25$ & 69 & 16.8 & 1.00 & \\
\hline \multicolumn{5}{|c|}{ Body fat at baseline (\%) } \\
\hline$\geq 30$ & 130 & 31.5 & $5.80(2.76-12.19)$ & 0.0000 \\
\hline$<30$ & 136 & 7.4 & 1.00 & \\
\hline \multicolumn{5}{|l|}{ Stature $(\mathrm{cm})$} \\
\hline$\geq 159$ & 127 & 21.3 & $1.29(0.70-2.38)$ & 0.4094 \\
\hline$<159$ & 139 & 17.3 & 1.00 & \\
\hline
\end{tabular}

${ }^{*} P$-value for OR.

$\dagger$ Missing cases.

$\ddagger P$-value for linear trend.
Table 4 Final logistic regression model between 9 months postpartum weight retention $\geq 7.5 \mathrm{~kg}$ and selected variables for Brazilian women aged 18-45 years (Rio de Janeiro, 1999-2001)

\begin{tabular}{|c|c|c|c|}
\hline Variable & $\begin{array}{l}\text { Adjusted } \\
\text { odds ratio }\end{array}$ & $\begin{array}{l}95 \% \text { confidence } \\
\text { interval }\end{array}$ & $P$-value \\
\hline \multicolumn{4}{|l|}{ Total income (reais) ${ }^{*}$} \\
\hline Higher income $(\geq 870)$ & 1.00 & & \\
\hline Lower income $(<870)$ & 3.29 & $1.30-8.30$ & 0.0116 \\
\hline \multicolumn{4}{|l|}{ Ability to read a letter* } \\
\hline Yes & 1.00 & & \\
\hline No & 2.10 & $0.93-4.52$ & 0.0724 \\
\hline \multicolumn{4}{|l|}{ Skin colour* } \\
\hline White and mulatto (brown) & 1.00 & & \\
\hline Black & 1.89 & $0.84-4.00$ & 0.1301 \\
\hline \multicolumn{4}{|l|}{ Age category (years)* } \\
\hline $18-29$ & 1.00 & & \\
\hline $30-45$ & 2.00 & $0.99-4.00$ & 0.0531 \\
\hline \multicolumn{4}{|c|}{ Mother's age at first childbirth (years) $\dagger$} \\
\hline$\geq 23$ & 1.00 & & \\
\hline$<23$ & 2.80 & $1.12-7.02$ & 0.0282 \\
\hline \multicolumn{4}{|l|}{ Gestational weight gain $(\mathrm{kg}) \ddagger$} \\
\hline$<12$ & 1.00 & & \\
\hline$\geq 12$ & 4.77 & $1.81-12.55$ & 0.0015 \\
\hline \multicolumn{4}{|l|}{ Obesity (impedance) $\ddagger$} \\
\hline Body fat $<30 \%$ & 1.00 & & \\
\hline Body fat $\geq 30 \%$ & 10.21 & $4.13-25.23$ & $<0.0000$ \\
\hline \multicolumn{4}{|l|}{ Infant hospitalisation§ } \\
\hline No & 1.00 & & \\
\hline Yes & 2.21 & $0.90-5.45$ & 0.0825 \\
\hline \multicolumn{4}{|l|}{ Infant's birth weight $(\mathrm{g}) \S$} \\
\hline$\geq 3500$ & 1.00 & & \\
\hline$<3500$ & 2.54 & $0.94-6.85$ & 0.0662 \\
\hline
\end{tabular}

* Model 1: total family income, ability to read a letter, skin colour, age category.

† Model 2: model 1 plus mother's age at first childbirth.

$\ddagger$ Model 3: model 2 plus gestational weight gain, obesity (impedance).

$\S$ Model 4: model 3 plus infant hospitalisation, infant's birth weight.

logistic regression model showed that woman aged $\geq 30$ years presented a two-fold risk of retaining $\geq 7.5 \mathrm{~kg}$. Other variables that remained associated were total family income, ability to read a letter, mother's age at first childbirth, gestational weight gain and obesity measured by impedance.

Considering the lack of international agreement concerning what is high weight retention, we decided to adopt the cut-off of $7.5 \mathrm{~kg}$ at 9 months postpartum in the present study. This represented 19\% of this group of Brazilian women and also corresponded to 2.4 times the median weight retention value at 9 months postpartum, a substantial amount of weight retention. Thus, considering that the retained weight is mostly composed of body fat, women with this level of weight retention should be a priority for the health system, especially due to the high risk of developing obesity and the diseases resulting from it.

The important advantage of the present study is the application of the hierarchical approach proposed by Victora et $a l^{21}$. With this approach, we adjust the model only for variables with superior hierarchical effect. This means that model adjustment occurs according to predetermined relationships between predictors, grouped in blocks here, and there is no adjustment for all variables entering the model, as in regular logistic regression. 
A particularly interesting finding was that women with limited schooling, characterised herein by difficulty or inability to read a letter, and those with low total family income showed 2.10 and 3.29 times the risk of retaining $7.5 \mathrm{~kg}$ or more, respectively. This new pattern in the social distribution of obesity is in agreement with recent findings of Monteiro and Conde ${ }^{22}$ and Monteiro et al. $^{23}$ for the population of Brazilian women from the Southeast region, and for the country's urban population as a whole. However, it differs from previous observations by Sobal and Stunkard ${ }^{24}$, according to which there is a positive association between obesity and income among women in developing countries. The observation, according to our results, of increased risk of weight retention in social strata with lower incomes and less schooling confirms the hypothesis raised by both Brazilian ${ }^{22,25}$ and international authors $^{26}$, showing that the current trend is for obesity to be concentrated in the lower-income strata of women in developing countries, as already observed in developed countries. The effect of these factors can be understood by considering that women with low schooling tend to have greater difficulty in perceiving the risks associated with obesity, whilst women with lower incomes tend to be less able to choose the foodstuffs in their diet.

According to the bivariate analyses in the current study, black women showed a 2.54 times unadjusted risk of weight retention $\geq 7.5 \mathrm{~kg}$ as compared with white and brown (mixed-raced) women. After the bivariate analysis was adjusted for confounders, only a non-significant increased risk was observed. An association between colour and weight retention has already been reported in studies from the USA ${ }^{10,27,28}$. Another study of Brazilian women surveyed in the 1996 National Household Survey or PNDS also identified an association between skin colour and overweight ${ }^{4}$.

The analyses further demonstrated the independent effect of other determinant factors, such as high percentage of body fat $(\geq 30 \%)$ at baseline, age at first childbirth $<23$ years, and gestational weight gain of $12 \mathrm{~kg}$ or more.

Women with over $30 \%$ body fat at baseline had 10.21 times the risk of retaining $7.5 \mathrm{~kg}$ or more at 9 months postpartum, which can be expected, since it is supposed that nearly all of the weight retention consists of body fat. High pregnancy weight gain could be raised as a potential explicative hypothesis. The high pre-pregnancy overweight and obesity prevalence and the high obesity prevalence measured by impedance in this group of women also help to explain the phenomenon.

The association between age at first childbirth and weight retention following the current pregnancy has not been shown systematically in the literature, but has been identified previously as a predictor for the development of obesity (as measured by impedance) in women of childbearing age 29 . The proposed hypothesis is related to early initiation of the reproductive cycle, known to be associated with obesity ${ }^{30}$. According to Gunderson et al. ${ }^{31}$, an interval of less than 8 years between age at menarche and age at first childbirth is a predictor for the development of postpartum obesity. This variable can be considered a proxy for early pregnancy and is in agreement with the results reported here, where women who gave birth for the first time before the age of 23 years had 2.80 times the risk of retaining $7.5 \mathrm{~kg}$ or more during the postpartum period.

Gestational weight gain is by far the most important predictor of weight retention reported in the literature $\mathrm{t}^{7,10,12,32,33}$. All these studies reported greater postpartum weight retention for women with high gestational weight gain. A good example is the study by Ohlin and Rossner $^{32}$, where women with gestational weight gain in the 90th percentile retained $3.3 \mathrm{~kg}$, as compared with mothers in the 10th, who did not retain any weight at all. According to our data the mean gestational weight gain was $12.7 \mathrm{~kg}$ (minimum $-6 \mathrm{~kg}$, maximum $40 \mathrm{~kg}$ ) and is compatible with the results reported by Nucci et al. ${ }^{34}$ for over 3000 Brazilian pregnant women studied at six different capitals between 1991 and 1995. In our study, women with gestational weight gain of $12 \mathrm{~kg}$ or more had 4.77 times the risk of retaining $\geq 7.5 \mathrm{~kg}$ at 9 months postpartum. These results, and those of other authors $8,10,13,32$, reaffirm the importance of efficient nutritional intervention policies aimed at rigorous monitoring of weight gain during pregnancy.

One limitation of the current study is the use of selfreported pre-pregnancy weight. The problem consists in the potential underestimation of this variable by the vast majority of women, which could potentially lead to an overestimation of weight retention. In this study, since the pre-pregnancy weight was assessed at two distinct time periods, we were able to check the reliability of this specific information. Our results reveal a strong agreement between the two measures obtained. In general, studies from the international and Brazilian literature $e^{35-38}$ have already reported a high correlation between reported and measured weight, which minimises the potential bias from this type of information. In addition, it would be practically impossible to use the ideal information, which would be weight measured exactly after conception, as suggested by Gunderson and Abrams ${ }^{8}$, or even weight measured during the first trimester, as suggested by the Institute of Medicine ${ }^{39}$. The second limitation is the magnitude of losses to follow-up. While our values are consistent with those observed in other studies ${ }^{15,32}$, they could lead to questions about the validity of the final results. However, classical procedures on loss-to-followup pattern have shown that the losses are random, and thus do not interfere with the ultimate research findings. Another potential limitation consists in the use of a volunteer sample and the presence of bias on the generalisation of the findings. In this regard is important to mention that there is strong evidence which contests the potential selection bias that may derive from these 
situations. First, one of the recruitment sites offers a mandatory procedure which can be done only at public health centres, implying on a broad range of profiles. Second, although we do not have the desired external validity to generalise our results, there are data available showing that between 60 and $70 \%$ of Brazilian women of childbearing age attend public health care centres like the one used here ${ }^{34}$. In our opinion, these facts allow a limited, but important generalisation of the findings, which additionally are consistent with the literature.

What do the results of the current study actually tell us about the determinants of weight retention at 9 months postpartum for this group of Brazilian women? In short, an inverse relationship was observed between total family income, schooling and weight retention, and consequently obesity, with poorer women systematically at higher risk. As for the impact of nutritional variables, the results indicate the need for specific prenatal measures. Prenatal care actions should emphasise the control of gestational weight gain (before the 14th gestational week), with systematic weight surveillance across the whole gestational period; provide nutritional counselling, such as diets appropriate for controlling gestational weight gain; and highlight the importance of light physical activities ${ }^{18,40}$ or at least give encouragement to keep an active lifestyle ${ }^{28}$.

\section{Acknowledgements}

G.K. was supported by a fellowship from the Coordinating Body for Training University Level Personnel (CAPES). The project was supported by the following grants: José Bonifácio University Foundation of the Federal University of Rio de Janeiro (FUJB/UFRJ) and Rio de Janeiro State Research Foundation (FAPERJ).

\section{References}

1 World Health Organization (WHO). Obesity: Preventing and Managing the Global Epidemic. WHO Technical Report Series No. 894. Geneva: WHO, 1998.

2 Flegal KM, Carroll MD, Kuczmarski RJ, Johnson CL. Overweight and obesity in the United States: prevalence and trends, 1960-1994. International Journal of Obesity and Related Metabolic Disorders 1998; 22: 39-47.

3 Monteiro CA. Epidemiologia da obesidade. In: Halpern A, Matos AFG, Suplicy HL, Mancini MC, Zanella MT, eds. Obesidade. Porto Alegre: Lemos Editorial, 1999; 15-30.

4 Hidalgo CAG, Kac G, Velásquez-Meléndez G, Valente JG. Factors associated with overweight in Brazilian childbearing-age women according to skin colour. Nutrition Research 2002; 42: 785-94.

5 Mansur AP, Gomes EP, Avakian SD, Favarato D, Cesar LA, Mendes-Aldrighi J, et al. Clustering of traditional risk factors and precocity of coronary disease in women. International Journal of Cardiology 2001; 81: 205-9.

6 Visscher TL, Seidell JC. The public health impact of obesity. Annual Review of Public Health 2001; 22: 355-75.

7 Kac G. Fatores determinantes da retenção de peso: uma revisão da literatura. Cadernos de Saude Publica 2001; 17: 455-66.
8 Gunderson EP, Abrams B. Epidemiology of gestational weight gain and body weight changes after pregnancy. Epidemiologic Reviews 1999; 21: 261-75.

9 Linne Y, Barkeling B, Rossner S. Long term weight development after pregnancy. Obesity Reviews 2002; 3: $75-83$.

10 Keppel KG, Taffel SM. Pregnancy-related weight gain and retention: implications of the 1990 Institute of Medicine guidelines. American Journal of Public Health 1993; 83: 1100-3.

11 Lederman SA. The effect of pregnancy weight gain on later obesity. Obstetrics and Gynecology 1993; 82: 148-55.

12 Muscati SK, Gray-Donald K, Koski KG. Timing of weight gain during pregnancy: promoting fetal growth and minimizing maternal weight retention. International Journal of Obesity and Related Metabolic Disorders 1996; 20 : 526-32.

13 Abrams B, Selvim S, Gunderson EP. Pregnancy weight gain: still controversial. American Journal of Clinical Nutrition 2000; 71(Suppl.): 1233S-41S.

14 Coitinho DC, Sichieri R, Benicio MHDA. Obesity and weight change related to parity and breast-feeding among parous women in Brazil. Public Health Nutrition 2001; 4: 865-70.

15 Janney CA, Zhang D, Sowers M. Lactation and weight retention. American Journal of Clinical Nutrition 1997; 66: 1116-24.

16 Butte NF, Hopkinson JM. Body composition changes during lactation are highly variable among women. Journal of Nutrition 1998; 128(Suppl. 2): 381S-5S.

17 Kac G, Benício MHDA, Velásquez-Meléndez G, Valente JG, Struchiner CJ. Breastfeeding and postpartum weight retention in a cohort of Brazilian women. American Journal of Clinical Nutrition 2003; in press.

18 Lovelady CA, Garner KE, Moreno KL, Williams JP. The effect of weight loss in overweight, lactating women on the growth of their infants. New England Journal of Medicine 2000; 342 : $449-53$.

19 Lohman TG, Roche AF, Martorell R. Anthropometric Standardization Reference Manual. Champaign, IL: Human Kinetics Books, 1988.

20 Hosmer DM, Lemeshow S. Applied Logistic Regression, 2nd ed. New York: John Wiley, 1989.

21 Victora CG, Huttly SR, Fuchs SC, Olinto MTA. The role of conceptual frameworks in epidemiological analysis: a hierarchical approach. International Journal of Epidemiology 1997; 26: 224-7.

22 Monteiro CA, Conde WL. A tendência secular da obesidade segundo estratos sociais: Nordeste e Sudeste do Brasil, 1975-1989-1995. Arquivos Brasileiros de Endocrinologia e Metabologia 1999; 43: 186-94.

23 Monteiro CA, Benício MHDA, Conde WL, Popkin BM. Shifting obesity trends in Brazil. European Journal of Clinical Nutrition 2000; 54: 1-5.

24 Sobal J, Stunkard A. Socioeconomic status and obesity: a review of the literature. Psychological Bulletin 1989; 105: $260-75$.

25 Monteiro CA, Conde WL, Popkin BM. Independent effects of income and education on the risk of obesity in the Brazilian adult population. Journal of Nutrition 2001; 131: 881S-6S.

26 Martorell R, Khan LK, Hughes ML, Grummer-Strawn CM. Obesity in women from developing countries. European Journal of Clinical Nutrition 2000; 54: 246-52.

27 Parker JD, Abrams B. Differences in postpartum weight retention between black and white mothers. Obstetrics and Gynecology 1993; 81: 768-74.

28 Lederman SA, Alfasi G, Deckelbaum RJ. Pregnancyassociated obesity in black women in New York City. Maternal and Child Health Journal 2002; 1: 37-42.

29 Kac G, Velásquez-Meléndez G, Valente JG. Menarca, gravidez precoce e obesidade em mulheres Brasileiras 
selecionadas em um Centro de Saúde de Belo Horizonte. Cadernos de Saude Publica 2003; 19(Suppl. 1): S111-8.

30 Lovejoy JC. The influence of sex hormones on obesity across the female life span. Journal of Women's Health 1998; 7 $1247-56$.

31 Gunderson EP, Abrams B, Selvin S. The relative importance of gestational gain and maternal characteristics associated with the risk of becoming overweight after pregnancy. International Journal of Obesity and Related Metabolic Disorders 2000; 24: 1660-8.

32 Ohlin A, Rossner S. Maternal body weight development after pregnancy. International Journal of Obesity 1990; 14: $159-73$.

33 Lederman SA. Pregnancy weight gain and postpartum loss: avoiding obesity while optimizing the growth and development of the fetus. Journal of the American Medical Women's Association 2001; 56: 53-8.

34 Nucci LB, Duncan BB, Mengue SS, Branchtein L, Schmidt MI, Fleck ET. Assessment of weight gain during pregnancy in general prenatal care services in Brazil. Cadernos de Saude Publica 2001; 17: 1367-74.
35 Stewart A, Jackson R, Ford M, Beaglehole R. Underestimation of relative weight by use of self-reported height and weight. American Journal of Epidemiology 1987; 125: 122-6.

36 Schmidt MI, Duncan BB, Tavares M, Polanczyk CA, Pellanda L, Zimmer PM. Validity of self-reported weight - a study of urban Brazilian adults. Revista de Saude Publica 1993; 27 : 271-6.

37 Lederman SA, Paxton A. Maternal reporting of prepregnancy weight and birth outcome: consistency and completeness compared with clinical record. Maternal and Child Health Journal 1998; 2: 123-6.

38 Chor D, Coutinho ESF, Laurenti R. Reliability and selfreported weight and height among state bank employees. Revista de Saude Publica 1999; 33: 16-23.

39 Institute of Medicine, Subcommittee on Nutritional Status and Weight Gain during Pregnancy. Nutrition During Pregnancy. Washington, DC: National Academy of Sciences, 1990.

40 Dewey KG. Effects of maternal caloric restriction and exercise during lactation. Journal of Nutrition 1998; 128 $3865-9 S$. 